\title{
Recuperação e reabilitação arquitetônicas do Anfiteatro de Imagem, Luz e Som de Irani/SC
}

A relação das cidades com seu Patrimônio Cultural, bem como a necessidade de valorizá-lo e preservá-lo como imprescindivel à formação da identidade e memória coletivas é de fundamental importância às relações sociais. Em vista disso, o presente estudo surge como embasamento teórico voltado ao desenvolvimento do anteprojeto arquitetônico de recuperação e reabilitação do Anfiteatro de Imagem, Luz e Som de Irani (SC). Como objetivo de devolver ao monumento arquitetônico, sua função como lócus turístico e cultural da região do Vale do Contestado e sua importância como espaço destinado às manifestações artísticas locais. Por meio da pesquisa documental, buscou-se a elucidação da temática com ênfase na história regional, suas representações e legado, maiormente voltados aos seus vínculos como Patrimônio Cultural e os aspectos projetuais, visando desenvolver o anteprojeto de forma a suprir as necessidades locais e respeitando seu contexto histórico imanente. Assim, consolidaram-se como resultados o desenvolvimento do anteprojeto arquitetônico proposto, bem como o valor da temática abordada e sua importância para a preservação e valorização do Patrimônio local e da necessidade do município e região em possuir espaços voltados à educação artística, às representações do Contestado através do teatro e das produções culturais, de modo a estabelecer a relação identitária entre o passado e o presente e garantir sua repercussão permanente como história e legado.

Palavras-chave: Recuperação e reabilitação; Anfiteatro; Irani.

\section{Architectural recovery and rehabilitation of the Image, Light and Sound Amphitheater of Irani/SC}

\begin{abstract}
The relationship of cities with their Cultural Heritage, as well as the need to value and preserve it as essential to the formation of collective identity and memory is of fundamental importance to social relations. In view of this, the present study appears as a theoretical basis aimed at the development of the architectura project for the recovery and rehabilitation of the Amphitheater of Image, Light and Sound of Irani (SC). In order to give back to the architectural monument its function as a tourist and cultural locus in the Vale do Contestado region and its importance as a space for local artistic manifestations. Through documentary research, we sought to elucidate the theme with an emphasis on regional history, its representations and legacy, mostly focused on its ties as Cultural Heritage and project aspects, aiming to develop the preliminary project in order to meet local needs and respecting its immanent historical context. Thus, the development of the proposed architectural project was consolidated as a result, as well as the value of the theme addressed and its importance for the preservation and valorization of the local Heritage and the need of the municipality and region to have spaces dedicated to artistic education, to the representations of the Contested through theater and cultural productions, in order to establish the identity relationship between the past and the present and guarantee its permanent repercussion as history and legacy.
\end{abstract}

Keywords: Recovery and rehabilitation; Amphitheater; Irani.

Topic: Arquitetura e Urbanismo

Reviewed anonymously in the process of blind peer.
Received: 08/11/2019

Approved: $17 / 03 / 2020$
Leonardo Gazzoni (id)

Universidade do Oeste de Santa Catarina, Brasil

http://lattes.cnpq.br/8662875924535422

https://orcid.org/0000-0002-4440-781X

leonardogazzonileo@gmail.com

Anderson Saccol Ferreira (iD

Universidade do Oeste de Santa Catarina, Brasil

http://lattes.cnpq.br/4850843904897537

https://orcid.org/0000-0002-6237-9912

anderson.ferreira@unoesc.edu.br

Erickson Rodrigues do Espírito Santo ic

Universidade do Oeste de Santa Catarina, Brasil

http://lattes.cnpq.br/5902128620830709

http://orcid.org/0000-0001-9736-8984

erickson.santo@unoesc.edu.br

DOI: 10.6008/CBPC2674-6425.2020.002.0002
Referencing this:

GAZZONI, L.; FERREIRA, A. S.; SANTO, E. R. E.. Recuperação e reabilitação arquitetônicas do Anfiteatro de Imagem, Luz e Som de Irani/SC. Technology Science, v.2, n.2, p.14-29, 2019. DOI: http://doi.org/10.6008/CBPC2674-6425.2020.002.0002 


\section{INTRODUÇÃO}

Resguardar a memória de uma região e de fatos históricos fundamentais para a formação geográfica, econômica e social desta é, sobretudo, proteger o que há de mais valioso à concepção de uma identidade local e, portanto, seu Patrimônio Cultural. Neste contexto patrimonial e de valorização histórica, surge como estigma à memória da região Meio-Oeste catarinense a Guerra do Contestado, conflito armado ocorrido durante os anos de 1912 a 1916 entre os pequenos proprietários das terras ricas em erva mate e madeira contra forças militares federais e paranaenses, culminando na morte de milhares de pessoas, sendo a maioria caboclos pobres que resistiam à espoliação das expedições militares pela exploração da terra (LINO, 2012).

O município de Irani (SC), por se destacar como cenário do primeiro combate entre os sertanejos e as tropas militares, desde a década de 70 possui gestões políticas empenhadas em desenvolver formas de apropriação do local onde ocorreu o combate e transformá-lo em um espaço de memória do Contestado, incluindo seu tombamento como patrimônio cultural do Estado (RICHTER, 2013). Foi no início dos anos 2000, contudo, que as pretensões voltadas à valorização cultural e ao desenvolvimento do turismo na região de Irani encontraram subsídio e, por meio do incentivo do governo estadual, deu-se corpo ao projeto e construção do Parque Temático do Contestado, com uma série de estruturas dispostas a fortalecer a gênese histórica do município. Todavia, grande parte dos espaços previstos no projeto original do Parque não foram executados ou, vítimas do descaso e da falta de investimentos por parte das gestões subsequentes, abandonados durante a sua construção, como é o caso do Anfiteatro que hoje figura no local como ruína.

Neste contexto, a principal questão de pesquisa se volta à ideia de como atuar na recuperação do patrimônio arquitetônico inconsolidado em Irani/SC, de forma a dar continuidade na sua proposta cultural. Como objetivo pretendemos desenvolver o anteprojeto arquitetônico de recuperação e reabilitação do Anfiteatro de Imagem, Luz e Som de Irani/SC, bem como de suas estruturas adjacentes, no intuito de reinserir a obra como lócus turístico e artístico do Vale do Contestado, na sua função de símbolo à expressão legítima do povo caboclo. Atribuem-se como procedimentos metodológicos adotados neste estudo, a pesquisa documental acerca da temática exposta com ênfase na história regional, suas representações e legado, maiormente voltada aos vínculos com o Patrimônio Cultural do Contestado, bem como a análise de levantamentos e considerações técnicas, contemplando análises de área, inserção urbana, estudos de impacto da obra em sua implantação e, por fim, a proposta arquitetônica em si, apontando os principais conceitos e percepções de projeto, sua relação com a conjuntura histórica local e a abordagem estética, vista pelo estudo da forma, materiais e elementos que compõem sua arquitetura.

Como resultados, desenvolvemos um anteprojeto arquitetônico de recuperação das estruturas degradadas do Anfiteatro e a proposição de novos blocos destinados a abrigar diferentes atividades, vindo ao encontro dos interesses do corpo cultural e artístico do município e região, de forma a atuar no fortalecimento do viés turístico local e no enaltecimento da memória viva de seu povo e de sua história. 


\section{METODOLOGIA}

\section{A valorização e resgate da memória: formação do patrimônio do Contestado}

A necessidade de compreensão do arranjo histórico e social do planalto sul brasileiro, sobretudo no início do século XX, torna-se questão de grande relevância a fim de se traçar um panorama sobre a formação territorial e social da região. Localizada no Meio-Oeste de Santa Catarina, a região do atual Vale do Contestado foi o epicentro das disputas lindeiras entre Brasil e Argentina no século XIX e, posteriormente, entre os estados de Santa Catarina e Paraná, advindo daí o nome 'Contestado'. Para tanto, compete à historiografia ressaltar a ocupação do território, timidamente tomado pelas frentes europeias colonizatórias devido à expansão pecuária decorrente dos caminhos das tropas, atravessando os campos desde o Rio Grande do Sul até São Paulo (LINO, 2012).

Rios (2013) observa que, nas terras do planalto, aos poucos iam se fundando entrepostos, pousadas, arraiais, oficinas, ferrarias. Surgidos deste cenário de miscigenação e diversidade, os caboclos, então posseiros do local, tiravam da terra seu sustento, sem acúmulo supérfluo ou que se desviasse do sentido único de sobrevivência. É neste contexto que as riquezas naturais locais, que começavam a ser desbravadas no período (predominantemente a madeira de alto valor comercial e as facilidades do cultivo da erva-mate), despertaram a atenção, sobretudo, do capital estrangeiro interessado nos investimentos em solo brasileiro e atentos no potencial extrativista subaproveitado do planalto sul.

As expectativas da República em desenvolver a região através da construção de uma ferrovia que ligaria os estados de São Paulo a Rio Grande do Sul estimulou a concessão, ao capital estrangeiro, de uma área de $7.000 \mathrm{~km}^{2}$ a ser desapropriada para a livre exploração da terra. O Estado do Paraná, por sua vez, reconheceu os direitos da empresa, sem estabelecer qualquer indenização aos caboclos posseiros ou prever novas glebas para assentá-los. Sem lhes valer a invocação de usucapião, os moradores foram despejados, seus casebres eram incendiados e as famílias lançadas ao mato (RIOS, 2013).

Começa a delinear-se, neste contexto, o conjunto de fatores de ordem política e econômica que deram início à Guerra do Contestado, conflito armado entre a resistência cabocla, ocupante das terras, e as forças do Estado impulsionadas pelo interesse privado. De 1912 a 1916, a população da região do Vale do Rio do Peixe foi vítima do coronelismo e do uso da espoliação e da violência, resultando nas mortes das inúmeras frentes de soldados e sertanejos dizimadas nas pelejas. Os corpos de milhares de combatentes, vítimas destes quatro anos de conflitos desencadeados a partir da Batalha do Irani, abrigam-se em valas espalhadas por toda a região contestada (MOURA, 2013).

Apesar do marco intenso que a Guerra do Contestado assinalou no semblante econômico e social, sobretudo no oeste de Santa Catarina durante os anos seguintes ao fim do combate, suas repercussões e legado se mantiveram, por um longo período, distantes das discussões políticas e da reflexão a respeito de seu contexto, principalmente por parte dos antigos moradores das áreas conflitantes que presenciaram os horrores dos motins e dos abusos de quem detinha o poder na época. Motta (2016) aponta que, durante décadas, o Brasil, o Sul, Santa Catarina e Paraná relegaram o Contestado ao esquecimento. Contudo, 
reminiscências do período turbulento na região permaneceram como que atadas nas famílias sertanejas e foram transmitidas tempos depois, quase que somente para as suas gerações posteriores, uma vez que seus parentes protagonistas também se calaram no pós-guerra, receando revelar aspectos que pudessem custar suas próprias vidas.

Neste contexto, as primeiras pontuações públicas após a Guerra Santa surgiram pela voz de tenentes, coronéis e generais que assinalavam o momento como de missões que buscavam pacificar a região, de forma a "libertar o país de males como o fanatismo, a ignorância e o banditismo" (RODRIGUES, 2001). Somente a partir da década de 1950, documenta Richter (2013), que alguns trabalhos acadêmicos começaram a avaliar os sertanejos do ponto de vista antropológico, tendo a alteridade ganhado novos contornos, não situando mais a figura cabocla na esfera do inculto ou do incivilizado, mas com um novo olhar sob a perspectiva humana em seu contexto heroico, justo e dotado de uma profunda noção de civismo e caráter.

Para Richter (2013), foi a partir das últimas décadas do século XX que se tornou possível verificar algumas questões relacionadas à atuação do Estado, na perspectiva de que começava-se a possibilitar uma nova compreensão acerca deste tema e seus desdobramentos no campo do Patrimônio Cultural, uma vez que o silêncio por parte do governo a respeito do Contestado seria quebrado por ações que buscariam não só enaltecer a população cabocla como virtude, mas estabelecer uma série de elementos que solidificassem uma memória dos acontecimentos, criando seu patrimônio na forma de datas comemorativas, símbolos e locais de apresentação ou exposição do tema Contestado.

Assim, a partir dos anseios de uma consolidação por meio do símbolo no contexto histórico-cultural é que, na década 80 , tiveram início uma série de promulgações e discursos exaltando a necessidade de valorização de elementos da cultura cabocla, bem como do passado histórico relacionado à guerra, dandose abertura ao Projeto de Resgate da Memória do Contestado. Neste período, fomentou-se a implantação de museus, monumentos, produções científicas e artísticas, sobretudo nos municípios que serviram de palco para a guerra, como o Museu do Contestado, em Caçador/SC, o Museu José Maria e a escultura 'Mãos de Cimento', em Irani/SC, instrumentos utilizados integralmente para se reelaborar uma memória para o Conte

Por sua vez, ao papel do estado na luta pelo reconhecimento e valorização da memória, soma-se a exímia atuação do historiador, músico e compositor iraniense Vicente Telles que, pelo caráter precursor e singular de sua obra desde a década de 70 , tornou-se figura de maior empenho quanto à salvaguarda e enaltecimento dos valores voltados à instituição de um Patrimônio do Contestado. Promovendo uma série de apresentações culturais, eventos artísticos, canções e dramatizações sobre a guerra, o folclorista foi o responsável pela divulgação do tema em escalas estaduais e nacionais de forma a "vincular a imagem de Irani à Guerra do Contestado, a fim de promover o turismo histórico no município" (MOTTA, 2016).

Na visão de Richter (2013), a atenção e investimento por parte do governo estadual durante a década de 1980 acabariam diminuindo; porém, haveria um novo recrudescimento durante o início dos anos 2000. Foi nesse período que tomou corpo a ideia da construção de um Parque Temático do Contestado em Irani. Este Parque (Figura 1), projeto do arquiteto Ires Lopes da Silva e idealizado por Telles, seria construído de forma a abranger o espaço tido como palco do enfrentamento entre soldados e sertanejos, de forma que: 
No projeto apresentado em 2001, constava a construção de uma capela, uma Casa da Memória, uma igreja (Capela do Monge), recepção para informações turísticas, linha férrea e estações para o deslocamento no interior do parque, cobertura de policarbonato no local do combate, uma "Cidade Santa" em formato de cruz com 24 edificações, anfiteatro com $642 \mathrm{~m}^{2}$ instalado em uma ilha artificial e arquibancada com 1.200 lugares instalada em um morro de forma a se integrar à paisagem. Enfim, o maior investimento público (estado e prefeitura) tendo a Guerra do Contestado como referência. (SILVA, 2017).

Planejado para ocupar uma área de $318.031,35 \mathrm{~m}^{2}$, o Parque seria implantado às margens da BR 153, Km 63, e foi concebido para funcionar como um centro de estudos, apresentações culturais e, principalmente, uma referência para o turismo histórico-cultural, capaz de diferenciar Irani dos demais municípios catarinenses no contexto da Guerra e nas abordagens artísticas a respeito (MOTTA, 2016).

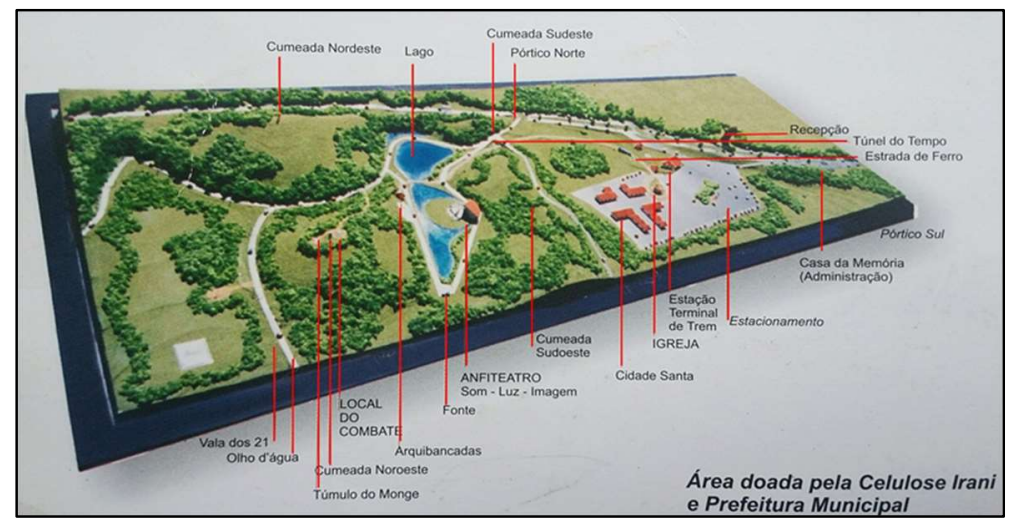

Figura 1: Maquete do Parque Temático do Contestado. Fonte: Silva (2002).

Este novo período de idealizações e incentivos governamentais foi relevante, também, para a afirmação do caráter simbólico e patrimonial do Contestado, com a promulgação de legislações específicas, reconhecendo a bandeira do Contestado como símbolo regional do Estado de Santa Catarina, sendo que esta poderia ser hasteada em eventos oficiais do Estado, e instituindo a Semana do Contestado, sendo comemorada anualmente entre os dias 20 e 27 de outubro, devendo o Poder Legislativo Estadual desenvolver debates e conferências, além de comemorações cívicas e históricas na rede escolar pública e particular (RICHTER, 2013).

Contudo, apesar da consolidação de ações favoráveis no âmbito legislativo, os demais projetos que tinham o intuito de fortalecer as relações da memória com o desenvolvimento do turismo regional não foram bem-sucedidos. Silva (2017) ressalta que, apesar das promessas de uma inauguração do Parque Temático em outubro de 2001, o projeto ficou incompleto. O espaço da guerra não recebeu a cobertura prometida, tendo sido executadas apenas trilhas e placas indicativas. Linha férrea, central de informações e a Cidade Santa se quer chegaram a sair do papel, enquanto que, das grandes construções prometidas, restaram apenas as obras inacabadas do anfiteatro, da ilha e das arquibancadas.

Quase vinte anos após as primeiras tentativas de engrandecer e favorecer as representações do Patrimônio Cultural do Contestado, observa-se que, igualmente a tantos e diversos descasos em relação à recuperação e fortalecimento de uma identidade regional, solidificada em seu contexto histórico, o Contestado também foi vítima da falta de interesse e incentivo por parte das gestões governamentais subsequentes. Fraga (2015) expõe que todo o Patrimônio envolvido se encontra abandonado no espaço e no 
tempo, e necessita ser resguardado, recuperado e posto à mostra da população e dos visitantes, tanto que "essa situação faz o Contestado em Guerra, pois as batalhas agora são, também, pela salvaguarda patrimonial regional" (FRAGA, 2015). Portanto, tais afirmações e contextualizações são tomadas como referências quanto a importância da consolidação de obras, a exemplo do Anfiteatro e do Parque Temático como um todo, para o estímulo do turismo e efetivação do Patrimônio Cultural e, partindo disso, estabelecer estratégias que possam contribuir para a concretização de seu espaço físico, além de uma visão, através da história, de como estes artefatos arquitetônicos contribuem para a formação da identidade e do vínculo social de seu povo.

\section{RESULTADOS E DISCUSSÃO}

\section{Aspectos regionais e análises de inserção urbana}

O anteprojeto arquitetônico de recuperação e reabilitação do Anfiteatro de Imagem, Luz e Som ambienta-se no município de Irani, localizado na região Meio-Oeste de Santa Catarina, Brasil. A grande estrutura degradada do Anfiteatro se situa em um terreno próximo às margens da BR-153, na área pertencente ao Sítio Histórico e Arqueológico do Contestado, distante cerca de 1,5 km do centro do município, conforme Figura 2.

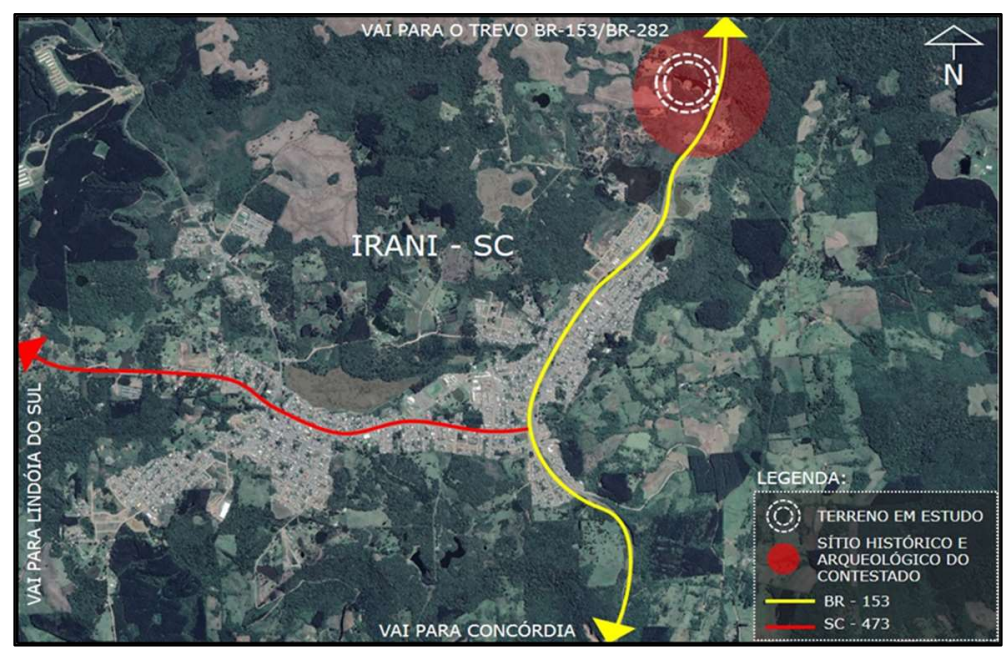

Figura 2: Inserção do terreno no município e sistema viário geral. Fonte: Adaptado do Google Earth (2018).

O terreno, doado pelo município e pela empresa Celulose Irani à Fundação Cultural Memória Viva do Contestado, situa-se conforme a Lei de Uso, Ocupação e Parcelamento do Solo do Município de Irani, na região da Macrozona Urbana, especificamente na Zona de Patrimônio Histórico do município, que tem por objetivo preservar a área de patrimônio histórico com parques públicos, evitando ocupações inadequadas e dotando o município de áreas públicas de turismo e lazer (IRANI, 2018). Em seu entorno, em um raio de 500 metros em relação ao terreno, observa-se a predominância de áreas de turismo histórico, na sua maioria voltadas ao Patrimônio Cultural do Contestado, como o Museu, Cemitério e Memorial, conforme ilustra a Figura 3. Obedecendo a Zona de Patrimônio Histórico, nota-se que há restrições da tipologia de construção permitida na localidade, e estas obedecem ao Anexo da VI da Lei Complementar no 91 de 24 de abril de 2018 , que trata da Classificação dos Usos permitidos em cada zona. 
Neste anexo, no que tange à estas Zonas, estabelece-se que são permitidos apenas os usos de Recreação e Lazer Especial 1 (ginásios, pequenas feiras eventuais, parques ambientais, praças e áreas de lazer); Recreação e Lazer Especial 2 (camping, parques de diversão, circos, associações de funcionários, parques de exposições e feiras de evento) e as atividades relacionadas aos centros históricos, como museus, salas especiais de eventos e atividades culturais, teatros, entre outros (IRANI, 2018).

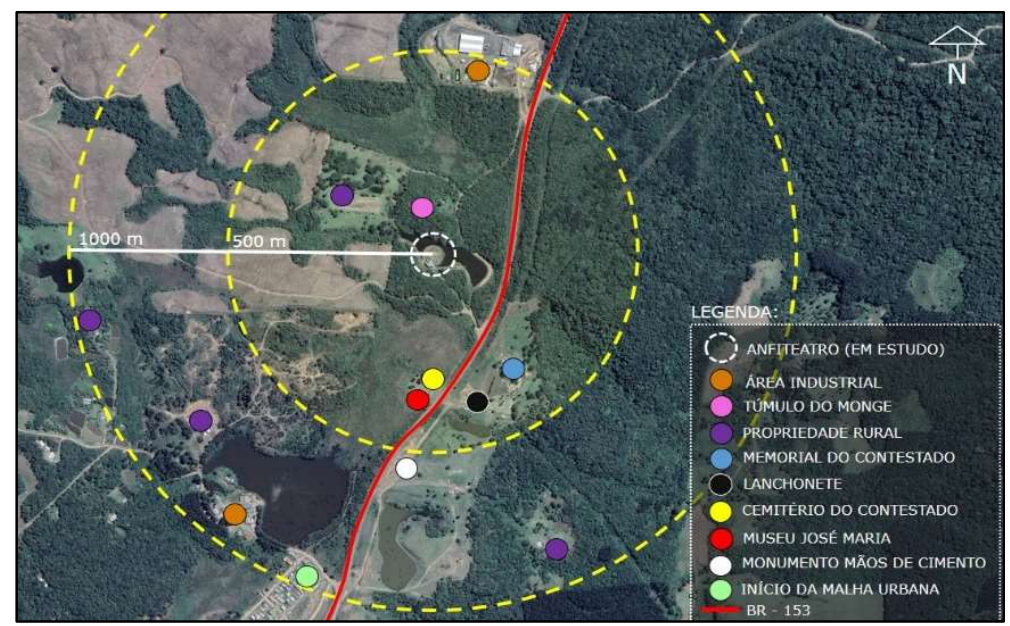

Figura 3: Vizinhança do empreendimento a 500m e a 1000m. Fonte: Adaptado do Google Earth (2018).

O acesso ao terreno se dá por vias rurais, de baixo tráfego e sem pavimentação ou quaisquer equipamentos de infraestrutura urbana, que se conecta diretamente ao tráfego intenso da BR-153 e servem de acesso aos turistas que visitam a área do Anfiteatro e do Sítio Histórico, bem como às propriedades rurais das proximidades. As estruturas do Anfiteatro inserem-se em uma ilha circular construída artificialmente em um lago, com área de aproximadamente $2000 \mathrm{~m}^{2}$.

Sua topografia se caracteriza por aclives circundando o terreno, de forma a situá-lo abaixo do nível da BR-153. As maiores altitudes se concentram próximo à locação das arquibancadas, que tiram proveito da topografia em aclive de forma a possuir uma visão ampla e desobstruída de todo o lago e do Anfiteatro. $O$ terreno está envolto por uma Área de Preservação Permanente, conforme Figura 4. De acordo com o previsto no Anexo II da Lei Complementar no 91 de 24 de abril de 2018 que trata dos Zoneamentos, em específico das Zonas de Preservação Permanente, essa faixa de vegetação bastante densa e abundante possui seus usos e ocupações restritos, com exceção dos usos públicos necessários e os voltados às atividades do centro histórico (IRANI, 2018).

Por situar-se em uma região de grande altitude em relação ao nível do mar, os ventos na área em estudo são geralmente intensos e constantes, possuindo predominantemente o sentido Sudeste (Figura 25). Porém, como a obra encontra-se cercada por uma topografia mais acentuada, as condições do próprio relevo atuam como barreiras naturais do terreno em relação à incidência de ventos mais fortes.

O local em estudo apresenta amplo potencial, principalmente no que tange à sua capacidade de abranger atividades voltadas ao estímulo cultural e artístico da região, bem como servir de rota turística de maior importância na abrangência do Vale do Contestado. Com o intuito de compreender os aspectos da área em estudo frente à sua conjuntura social, faz-se imprescindível contemplar, por sua vez, os principais 
dados técnicos e estatísticos correspondentes, de forma a solidificar as reais condições econômicas, sociais e culturais do município, compreendendo o desenvolvimento pertinente à cidade e vindo ao encontro, por meio da proposta arquitetônica, das necessidades ou anseios da população de sua abrangência.

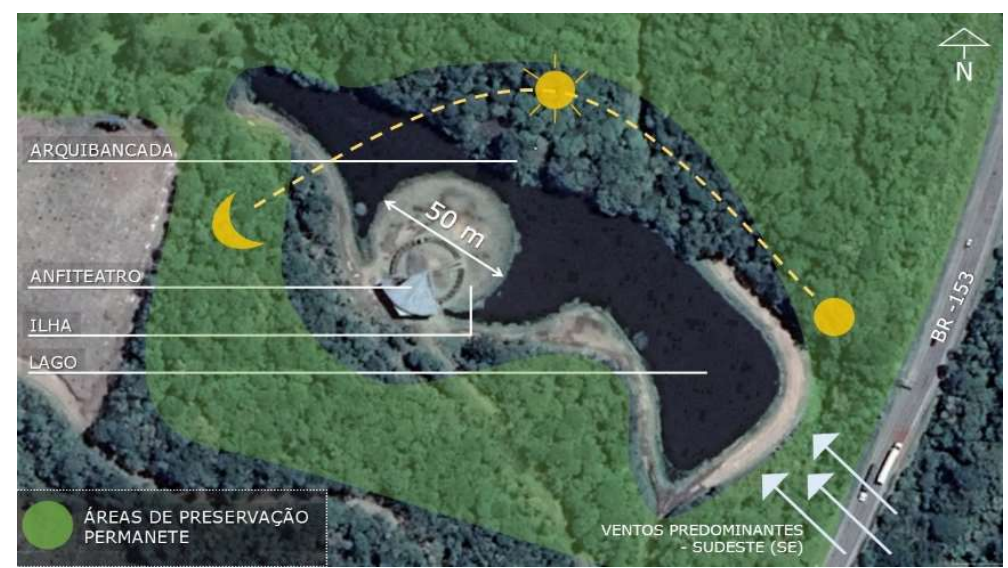

Figura 4: Áreas de Preservação Permanente e Condicionantes Climáticas. Fonte: Adaptado do Google Earth (2018).

A tabela 1, preconiza dados do município de Irani avaliados pelo Atlas de Desenvolvimento Humano do Brasil e pela Federação Catarinense de Municípios (FECAM) através do Sistema de Indicadores de Desenvolvimento Municipal Sustentável (SIDEMS), com base nos anos de 2010 a 2018, com o intuito de traçar um perfil consistente dos potenciais municipais nos quesitos que mais se aproximam do interesse da pesquisa (Tabela 1).

Tabela 1: Principais indicadores do município de Irani/SC.

\begin{tabular}{|l|l|}
\hline INDICADOR & ÍNDICE \\
\hline População & 10.285 habitantes \\
\hline Área & $325,737 \mathrm{~km}^{2}$ \\
\hline Índice de Desenvolvimento Humano Municipal (IDHM) & 0,742 \\
\hline Densidade demográfica & $28,82 \mathrm{hab} / \mathrm{km}^{2}$ \\
\hline Produto Interno Bruto (PIB) & $\mathrm{R} \$ 190.182,91$ \\
\hline PIB per capita & $\mathrm{R} \$ 18.796,49$ \\
\hline Remuneração Média dos Trabalhadores Formais & $\mathrm{R} \$ 1.698,30$ \\
\hline Expectativa de vida & 75,8 anos \\
\hline Educação & 0,675 \\
\hline Expectativa de anos de estudo & 10,3 anos \\
\hline Analfabetismo & $6,33 \%$ \\
\hline Legislação de Proteção ao Patrimônio Cultural Material ou Imaterial & 01 (possui) \\
\hline Conselho de Política Cultural & 01 (possui) \\
\hline Plano Municipal de Cultura & 0 (não possui) \\
\hline Fundo Municipal de Cultura Exclusivo & 0 (não possui) \\
\hline Adesão ao Sistema Nacional de Cultura & 01 (possui) \\
\hline Investimento em Cultura per capita & $\mathrm{R} \$ 8,62$ \\
\hline Investimento em Cultura sobre a Receita Corrente Líquida & $0,36 \%$ \\
\hline
\end{tabular}

Conforme os dados apresentados, estabelece-se que o município de Irani possui um índice de Desenvolvimento Humano considerado alto (IDHM entre 0,700 e 0,799) e seus índices relativos à expectativa de vida, renda com base no PIB e Educação são os que mais se destacam dentro da média nacional. Outros fatores de necessária abordagem para compreensão das características socioeconômicas e culturais de Irani (SC), referem-se aos parâmetros de educação e cultura, principalmente os voltados aos índices de escolaridade e a abordagem cultural preconizada pelas gestões municipais no ano analisado, uma vez que a 
proposta se destina à criação de um espaço voltado ao desenvolvimento destes aspectos.

Estes parâmetros, no entanto, revelam resultados medianos considerando o forte apelo histórico do município e sua configuração na rota turística do Vale do Contestado. No indicador de Investimento em Cultura sobre a Receita Corrente Líquida, por exemplo, observa-se uma baixa percentagem em relação a Receita Corrente Líquida do respectivo ano, gerando o debate acerca da necessária destinação de um montante maior de recursos às atividades culturais envolvidas. Neste sentido, percebe-se um impasse referente a menção de que o município possui políticas públicas a respeito, como no tangente à Legislação de Proteção ao Patrimônio, Conselho de Política Cultural e sua adesão à sistemas nacionais, ao mesmo tempo que as estatísticas evidenciam a falta de investimentos nas questões de preservação e cultura, mesmo que estas estejam regulamentadas e previstas pela legislação municipal.

Tais constatações solidificam a proposta de recuperação e reabilitação arquitetônicas do Anfiteatro como viáveis e de notável necessidade, visando a retomada dos investimentos culturais por parte da gestão municipal, podendo-se partir à angariação de fundos junto ao Estado, ao mesmo tempo em se faça novo e integral fomento ao turismo local e que, como consequência, trará resultados à economia do município e região.

\section{Proposta arquitetônica para o Anfiteatro de Imagem, Luz e Som de Irani}

O projeto propõe a recuperação das estruturas do Anfiteatro de Imagem, Luz e Som de Irani, bem como a reabilitação de seus espaços e a readequação destes às novas necessidades do programa cultural do município, incluindo sobre o projeto atual novas perspectivas e atividades a fim de permitir que a obra cumpra sua função original de inserir-se como símbolo turístico, artístico e cultural atuante na região do Contestado. O projeto original, de autoria do arquiteto Ires Lopes da Silva, consiste em um espaço voltado às apresentações artísticas como teatro, música e dança, inserido em uma ilha artificial cujas águas representam o cerco de Santa Maria pelos quatro pontos cardeais, dentro de um antigo banhado, esgotado para formar um lago. Nesta ilha, organizam-se os espaços técnicos e camarins, as arquibancadas em semicírculo cobertas por policarbonato, o palco, o anfiteatro em si. Ainda nesta redoma, a ilha forma um palco externo circular para as encenações das batalhas e apresentações com cavalaria e, às margens do estreito do lago, uma arquibancada inserida no meio da vegetação, com vista para toda a obra (TELLES, 2013).

Atualmente em ruínas (Figura 5), as obras do Anfiteatro foram iniciadas no ano de 2002 e interrompidas devido à falta de recursos; porém, sua proposta arquitetônica representa o período áureo em que as questões do Contestado foram amplamente valorizadas, de forma que projetos ambiciosos da época, como o Parque Temático do Contestado, do qual a obra do anfiteatro faria parte, tornaram-se destino de recursos e incentivos governamentais a fim de se tornarem memória efetiva e consolidada da Guerra do Contestado.

Visto o uso das formas simples como símbolo da cultura e dos hábitos caboclos e o caráter representativo destes através da arquitetura, faz-se necessário que as intervenções arquitetônicas respeitem seu conceito e adotem, nas suas novas proposições, o mesmo apelo formal voltado à conexão com o meio, 
com o contexto histórico local e a valorização da estética como reflexo dos princípios que fazem parte da linguagem introspectiva da obra.

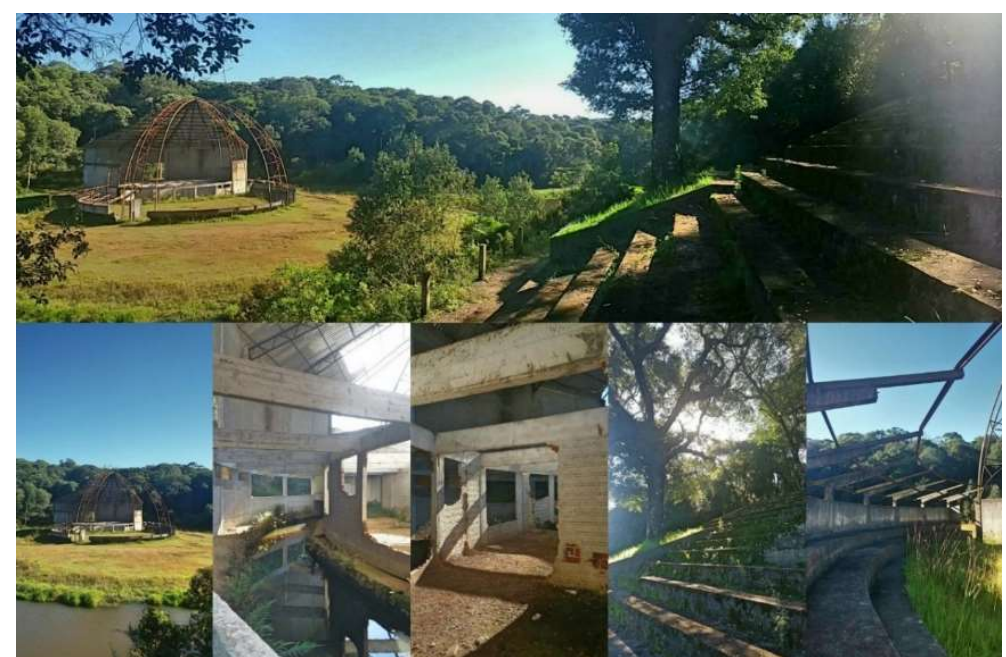

Figura 5: Atuais ruínas da estrutura do Anfiteatro e arquibancadas.

Assim, no intuito de compreender a proposta original e a necessidade de mantê-la como símbolo, verifica-se que projeto possui um programa bastante simples, totalizando $642 \mathrm{~m}^{2}$, distribuídos em um único pavimento térreo encimado de um palco, na cobertura dos camarins, de forma a facilitar a visibilidade a partir das arquibancadas no continente, conforme Figura 6. Uma estrutura metálica de perfis curvos (Figura 7) se ergue a 15 metros a partir do térreo e sustenta a cobertura de zinco que protege o palco das chuvas e da insolação constante.

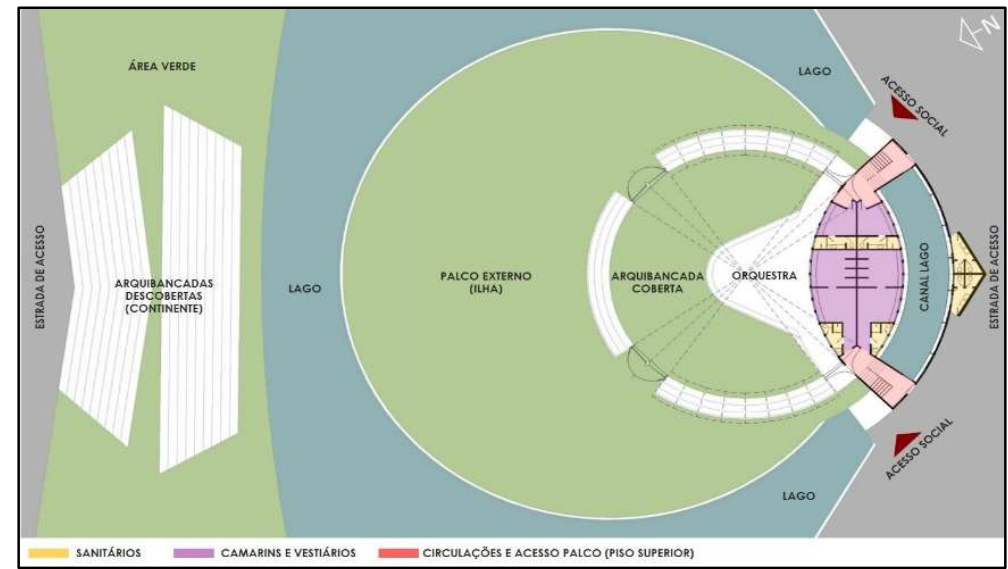

Figura 6: Planta Baixa do Anfiteatro. Fonte: Adaptado de Silva (2001).

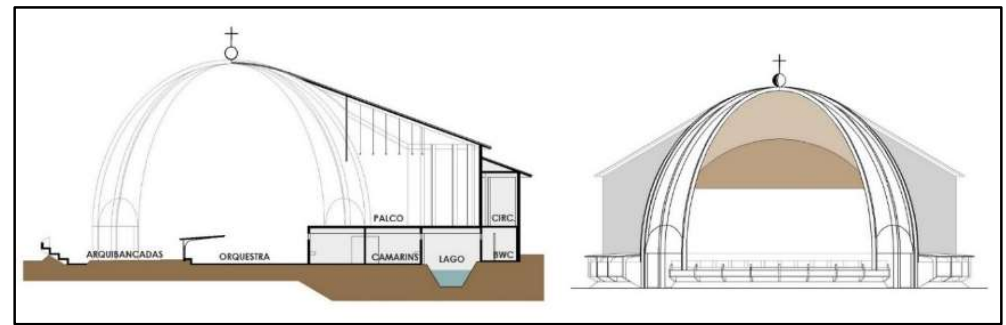

Figura 7: Corte esquemático e Elevação Norte do Anfiteatro. Fonte: Adaptado de Silva (2001).

Todas as intervenções propostas ao Anfiteatro de Imagem, Luz e Som de Irani dar-se-ão a partir da premissa primordial do projeto: obedecer ao contexto do projeto original, concebido como uma releitura da 
'Epopeia do Contestado', exaltada na obra poética e musical do historiador e folclorista Vicente Telles, que durante toda sua vida lutou pela valorização de um sentimento acerca do Contestado e pela preservação da memória. Sua extensa obra repercute com veemência no imaginário do povo de Irani, no sentido de contemplar e servir de elo entre a história, o folclore e a cultura viva junto à comunidade, trazendo em suas produções a severa crítica aos moldes exploratórios durante a Guerra do Contestado e, sobretudo, a glorificação do caráter puro, honesto, simples e valente da população cabocla frente às adversidades.

Desta forma, o conceito arquitetônico por trás de todo o processo de recuperação e reabilitação do espaço volta-se à síntese da simplicidade, equilíbrio e comunhão com o meio, característicos dos caboclos e ainda presente nos costumes e nas tradições iranienses e assinalados pelas produções artísticas valorosas de Telles.

O espaço será, portanto, de contemplação e encontro. Mais que isso, será lócus de formação, informação, respeito e memória fundamentais à criação de uma consciência cidadã nas gerações contemporâneas e futuras, de forma que sua estrutura aberta à integração com a natureza e a cultura seja capaz de ampliar a percepção dos visitantes na sua relação com a história, a memória e o espaço. Neste contexto, o partido arquitetônico surge como consequência dos aspectos conceituais, de forma que as intervenções propostas imprimam uma nova visão acerca da história, mas respeitando o conjunto existente. Portanto, neste caso é imprescindível que esta visão se integre também à forma do projeto, se tornando visível na volumetria e no planejamento de seus espaços como um todo.

Para atender às concepções do conceito, o partido busca nas formas simples, abertas e curvadas a representação da conexão com o passado, visto também nos materiais utilizados como relação intrínseca com as raízes da população cabocla em suas primeiras moradias. Por sua vez, nas novas edificações propostas nascerá uma nova perspectiva: o reflexo, aquilo que toma o passado como referência para se projetar ao futuro em uma nova realidade, como um olhar novo sobre a vida e o tempo.

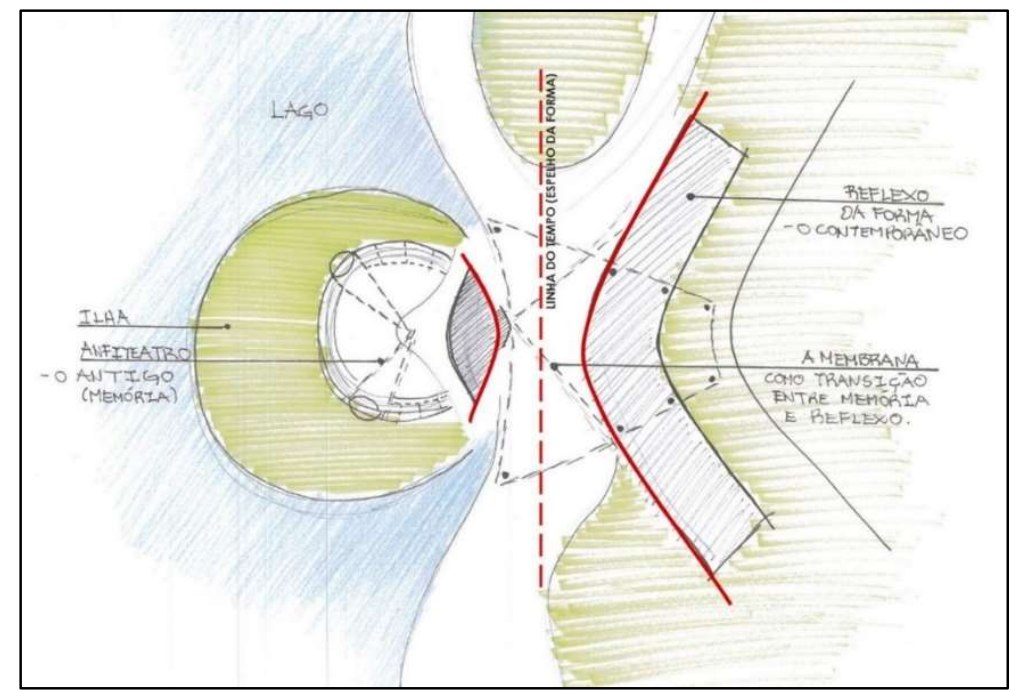

Figura 8: Croqui do anteprojeto em Planta Baixa. Fonte: Gazzoni (2019).

A Figura 8 corrobora o partido arquitetônico na conceituação da sua forma e em como esta adapta o sentido do 'reflexo' da forma simples e pura como norte da concepção plástica no projeto. Assim, as formas 
das construções anexas projetadas obedecem a imagem curva e semicircular do tradicional e do concreto das instalações do Anfiteatro, mas serão refletidas como se voltadas ao espelho da memória, e através dele será traçada a sua força e constância, como memória viva e repercutindo perenemente nas gerações vindouras por meio da arte. Esse reflexo tomará os traços da modernidade nas intervenções, mas manterá como intenção primordial a virtude e o respeito com a natureza em seu aspecto de sagrado, manifestado como herança e patrimônio intangível das populações que lutaram por suas terras.

A proposta de recuperação e reabilitação do espaço tem como prioridade manter as atividades originais voltadas às manifestações artísticas do município, readequando a estrutura para atender as normas de acessibilidade e desempenho voltadas às edificações de uso público e às apresentações teatrais, além de melhorias técnicas como a substituição das estruturas metálicas já executadas e o planejamento de rotas acessíveis em toda sua extensão.

Além do exposto, o projeto de reabilitação ainda prevê a construção de um novo módulo adjacente ao edifício existente, que funcionará como Centro Artístico e Cultural do Anfiteatro, surgindo como complemento à formação educacional das escolas do município e abrigando em sua estrutura salas para ensino das artes plásticas, música, teatro, dança, oficinas de produção artesanal e literária, além da criação do espaço da Biblioteca da Fundação Memória Viva do Contestado, destinada ao acervo das produções bibliográficas e estudos com foco na temática. Também se projetou, na porção fronteira ao anfiteatro e junto das arquibancadas originais, o Espaço Café do Anfiteatro, com o intuito de atender o público durante os eventos e apresentações no local. Este espaço funcionará por meio de parceria público-privada, concedendo o espaço público da estrutura à iniciativa privada, que melhor poderá atuar na manutenção do espaço.

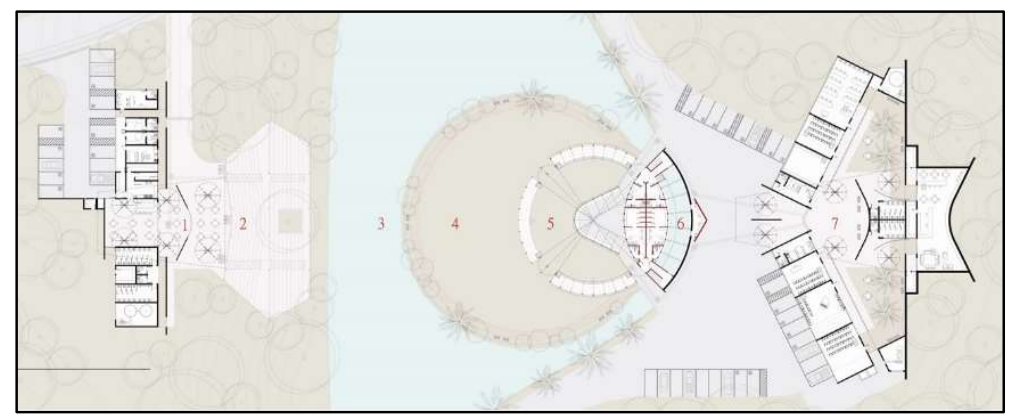

Figura 9: Implantação da proposta. Fonte: Gazzoni (2019).

1. Espaço Café do Anfiteatro

2. Arquibancada principal

3. Lago Artificial
4. Ilha (palco externo)

5. Arquibancadas próximas ao palco

6. Anfiteatro existente

Conforme previsto no Plano Diretor do município de Irani e atendendo ao disposto no Anexo da VI da Lei Complementar no 91 de 24 de abril de 2018, as obras de cunho histórico-cultural localizadas na Zona de Patrimônio Histórico dispensam locação de espaços exclusivos para estacionamento, uma vez que já está previsto no projeto do Parque Temático do Contestado uma extensa área para este fim e que atende a todas as obras arquitetônicas do complexo, possuindo uma localização de fácil acesso. Parte deste estacionamento previsto já foi implantada e possui uso efetivo do Museu José Maria e do Cemitério do Contestado, ambos em pleno funcionamento. 
O estacionamento previsto no projeto original servirá também aos usos do público do Anfiteatro, uma vez que nos arredores do edifício em questão não é possível construir grandes áreas de estacionamento observando as Áreas de Preservação Permanente (APP) em quase todo seu contorno, e também de forma a respeitar o contexto do local voltado às apresentações a céu aberto e o caráter simbólico e sagrado associado ao local, evitando o trânsito assíduo de automóveis em seu entorno, dispondo apenas de algumas vagas especiais e destinadas ao uso de funcionários. De forma a obedecer ao ideal preconizado na definição de conceito e partido arquitetônico do anteprojeto, os materiais utilizados na proposta buscam a confluência perfeita entre as raízes caboclas e as soluções contemporâneas, no sentido de proporcionar uma arquitetura funcional, de qualidade e em constante diálogo com o meio.

Nas obras do Anfiteatro serão recuperadas/reconstruídas as paredes em alvenaria dos camarins e áreas técnicas, bem como as estruturas curvas em aço que sustentam a cobertura do palco. Esta última, por sua vez, será substituída, uma vez que foi executada em telhas de zinco que não apresentam bom desempenho térmico e acústico, principalmente considerando as necessidades sonoras que o ambiente exige. Os arcos em aço, por sua vez, serão reestruturados para sustentar uma nova cobertura, em concreto armado, criando um espaço de concha acústica (Figura 10), melhorando o desempenho quanto ao direcionamento do som voltado às arquibancadas fronteiras ao palco, este que receberá piso em madeira, conforme projeto original.

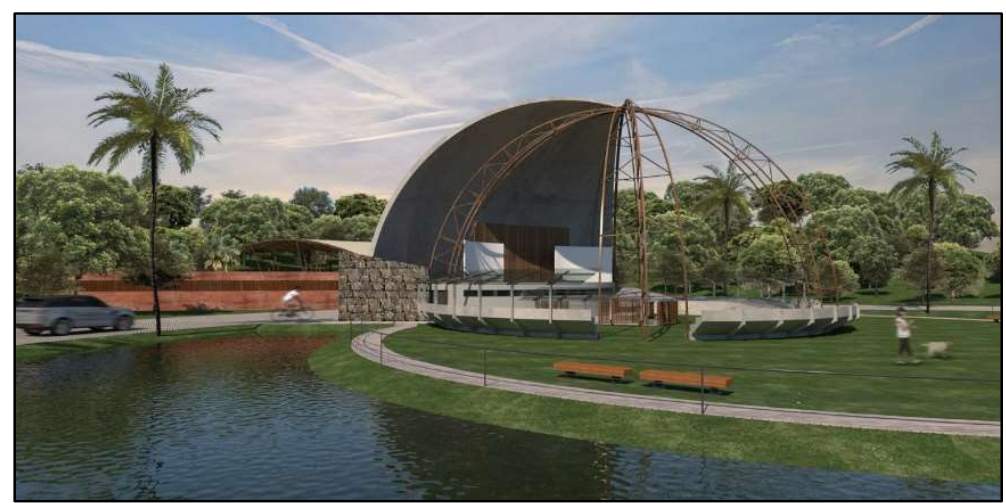

Figura 10: Perspectivas externas da proposta. Fonte: Gazzoni (2019).

Nas novas construções, fez-se uso predominante do concreto armado e taipas de pedra, bem como da madeira de eucalipto e do bambu Guadua Augustifolia, conhecido como 'taquaruçu' e de abundância na região do Vale do Contestado, remetendo aos materiais das construções primitivas na região e utilizado como símbolo da cultura cabocla.

Com o intuito de transmitir uma iluminação tênue nos espaços de circulações comuns do Centro Artístico e Cultural e do Espaço Café, membranas arquitetônicas em fibra de vidro revestido com polímero à base de flúor (PTFE) foram utilizadas, tensionadas por cabos de aço e apoiada pelas estruturas metálicas que conferem o aspecto contemporâneo do projeto (Figuras 11 e 12), ao mesmo tempo em que se conectam ao espaço antigo de forma que, visualmente, os espaços se integrem e formem um microclima comum.

As áreas cobertas pela membrana representam a transição do conteúdo histórico e, portanto, do passado fortificado pelo Anfiteatro, ao ambiente multifuncional e de expansão de conhecimentos dos novos 
blocos, representando o futuro. A membrana é, justamente pelo seu caráter tênue e delicado, a conexão entre ambos os espaços, como que consolidando a ideia de que a memória é o componente-chave para a compreensão da história e do próprio presente como visor das prospecções futuras.

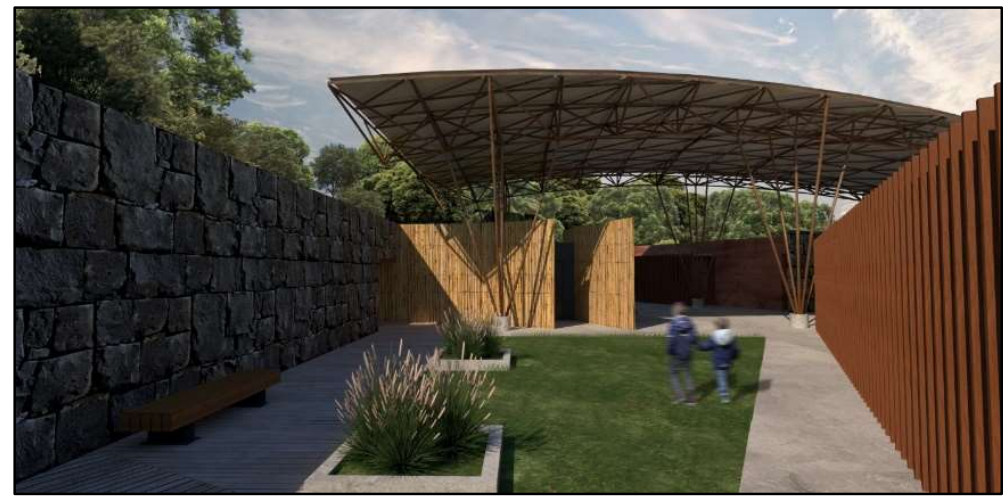

Figura 11: Perspectivas do Centro Artístico e Cultural do Anfiteatro. Fonte: Gazzoni (2019).

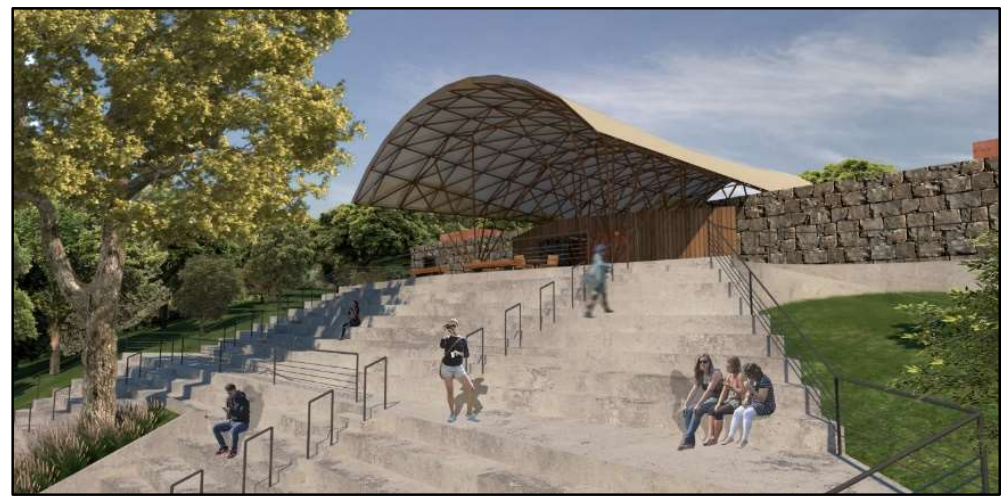

Figura 12: Perspectivas do Espaço Café do Anfiteatro e Arquibancadas a serem recuperadas. Fonte: Gazzoni (2019).

Desta forma, a proposta arquitetônica vista sob o seu conceito, partido arquitetônico e uso de materiais, objetiva transformar o espaço de abandono e descaso do Anfiteatro em um complexo cultural e turístico de amplo potencial, priorizando o semblante histórico característico, mas ampliando seu vínculo com o presente através de seu programa, do uso racional da forma, da consciência funcional de seus métodos construtivos e da preservação, unânime e justa, de uma memória viva na expressão de sua arte.

\section{CONCLUSÕES}

A arquitetura como espaço voltado às manifestações artísticas e culturais de um povo e de uma determinada região, além de sua função usual e pragmática de atender as necessidades e determinações de projeto, desempenha um incomensurável papel quanto à formação de uma identidade local, servindo como expressão atuante de seu tempo e sua história. Objetivando desenvolver o anteprojeto de recuperação e reabilitação das estruturas do Anfiteatro de Imagem, Luz e Som de Irani (SC), percebeu-se por meio da pesquisa documental e de análises projetuais e de território, o contexto por trás da abordagem do Patrimônio Cultural que a obra existente representa, seu impacto sobre a região com ênfase nas questões históricas e de preservação da memória, bem como a importância da elaboração de uma proposta arquitetônica que venha a dar continuidade ao projeto original, readequando este espaço às novas necessidades do município e região. 
Cumprindo seus objetivos quanto ao embasamento e compreensões teóricas envolvidas, o estudo abre espaço, a fim de sua consolidação efetiva, ao desenvolvimento do anteprojeto arquitetônico em si. Para tanto, respeitando as concepções originais do projeto e seu contexto, nova estruturas foram propostas de forma a absorver as novas proposições e ampliar seu impacto sobre a formação artística e cultural da região do Vale do Contestado. Além do notável impacto econômico e de desenvolvimento no município de Irani (SC), vistos pelo estímulo de suas atividades turísticas, as intervenções propostas no Anfiteatro representam o reencontro da comunidade com suas raízes culturais, extensivo à toda área circunvizinha do município e que possui, através da história, relações intrínsecas com o Contestado e o povo caboclo, representando assim um forte impacto no fortalecimento das relações sociais da região abrangente.

Por seu caráter de pesquisa, além das constatações acerca da escassez de recursos e investimentos voltados aos espaços de preservação histórica e cultural, o presente estudo também denota que o desenvolvimento do anteprojeto de recuperação e reabilitação do Anfiteatro de Irani/SC abre espaço às novas interpretações e considerações acerca da consolidação do Parque Temático do Contestado como Patrimônio Histórico e Cultural de Santa Catarina, trazendo em voga a necessidade da consolidação de suas estruturas e do reforço do papel do município como principal lócus da Rota Turística do Contestado, devolvendo à região o destaque a nível estadual na preservação histórica e na formação cultural com foco nas suas manifestações artísticas. Fortalece-se, portanto, a relevância do projeto como instrumento consolidador de estratégias que sirvam à comunidade no presente, por seu caráter pedagógico e funcional, mas emprestando ao futuro a garantia de sua solidez, de forma igualitária e concisa. Desta forma, torna-se possível atuar convictamente no enriquecimento do Patrimônio material e imaterial local, visto como alicerce da identidade e da cultura de geração em geração.

\section{REFERÊNCIAS}

FRAGA, N. C.. Contestado, 100 anos em guerra: as batalhas seguem: a luta pelo patrimônio e espaços de memória. 2015.

GAZZONI, L.. Recuperação e Reabilitação Arquitetônicas do Anfiteatro De Imagem, Lu E Som De Irani/SC. Monografia (Bacharelado em Arquitetura e Urbanismo) - Universidade do Oeste de Santa Catarina, Xanxerê, 2019.

IRANI. Lei Complementar n. 91, de 24 de abril de 2018. Institui a Lei de uso, ocupação e parcelamento do solo do Município de Irani. Irani: DOE, 2018.

LINO, J. T.. A cultura material da Guerra do Contestado como documento histórico. Cadernos do CEOM, Chapecó, v.25, p.45-70, 2012.

MOTTA, A. P.. Mãos de cimento: as representações da Guerra do Contestado no imaginário de Irani, Santa Catarina. Revista Núcleo de Estudos Paranaenses da UFPR, Curitiba, v.2, p.25-54, 2016.

MOURA, A. P.. O Exército Brasileiro e a insurreição do Contestado. In: WEHLING, A.; ZEFERINO, A. C.; MOURA, A.
P.; AXT, G.; SANCHES, H. C. C.. Cem anos do Contestado: memória, história e patrimônio. Florianópolis: MPSC, 2013.

RICHTER, F. A.. A Guerra do Contestado: elaborações e transformações na Memória e Patrimônio Cultural. In: SIMPÓSIO NACIONAL DE HISTÓRIA DA ANPUH: CONHECIMENTO HISTÓRICO E DIÁLOGO SOCIAL, 27. Anais. Natal, 2013.

RIOS, J. A.. O Contestado: um centenário. In: WEHLING, A.; ZEFERINO, A. C.; MOURA, A. P.; AXT, G.; SANCHES, H. C. C. Cem anos do Contestado: memória, história e patrimônio. Florianópolis: MPSC, 2013.

RODRIGUES, R. R.. Os sertões catarinenses: embates e conflitos envolvendo a atuação militar na Guerra do Contestado. Dissertação (Mestrado em História) Universidade Federal de Santa Catarina, Florianópolis, 2001.

SILVA, I. L.. Projeto do Parque Temático do Contestado. Irani, 2001.

SILVA, I. L.. Parque Temático: histórico. In: TELLES, V.. Folclore Itinerante da Epopeia do Contestado: história em música. Irani, 2002. 
SILVA, L. C.. Museus do Paraná e Santa Catarina: formas de lembrar e esquecer a Guerra Sertaneja do Contestado (1912 - 2012). Tese (Doutorado em História) - Universidade Federal do Paraná, Curitiba, 2017.
TELLES, V.. O Memorial do Contestado: memória e cidadania no Irani. In: WEHLING, A.; ZEFERINO, A. C.; MOURA, A. P.; AXT, G.; SANCHES, H. C. C.. Cem anos do Contestado: memória, história e patrimônio. Florianópolis: MPSC, 2013.

A CBPC - Companhia Brasileira de Produção Científica (CNPJ: 11.221.422/0001-03) detém os direitos materiais desta publicação. Os direitos referem-se à publicação do trabalho em qualquer parte do mundo, incluindo os direitos às renovações, expansões e disseminações da contribuição, bem como outros direitos subsidiários. Todos os trabalhos publicados eletronicamente poderão posteriormente ser publicados em coletâneas impressas sob coordenação da Sapientiae Publishing, da Companhia Brasileira de Produção Científica e seus parceiros autorizados. Os (as) autores (as) preservam os direitos autorais, mas não têm permissão para a publicação da contribuição em outro meio, impresso ou digital, em português ou em tradução. 